\title{
Pengembangan Sekolah Berbasis Go Green dan Waste Management untuk Mewujudkan Green School di SDI Miftahul Huda Plosokandang Kabupaten Tulungagung
}

\section{Chusnul Chotimah}

IAIN Tulungagung

chusnultata@gmail.com,chusnultata@iaintulungagung.ac.id

\begin{tabular}{ll|l|l|l|l} 
Received : & June 19th 2019 & & Revised & : $\quad$ Oct 17th 2019 & Accepted
\end{tabular}

\begin{abstract}
In supporting the environmental conservation program, protecting the earth from damage caused by buman activities and unfriendly activities, it is necessary to instill early education about preserving the environment and conservating the earth free of garbage while reducing the impact of global warming. SDI Miftahul Huda Plosokandang Tulungagung care about it. This issue are green school and waste management was carried out the empowerment of educational institution. This study uses the Community Based Research (CBR) method with the Asset-Based Approach $(A B A)$ to empower schools to achieve green school and waste management. The results achieved by the school are able to integrate environmental awareness in the curriculum, create healthy living habits and using of a green environment based on green schools and waste management.
\end{abstract}

Keyword: Sekolah, Go Green, and Waste Management

\section{Pendahuluan}

Secara istilah go green merupakan gerakan hijau. ${ }^{1}$ Go green yang dilaksanakan di sekolah berarti gerakan sekolah hijau di lingkungan sekolah. Sedangkan sekolah yang melakukan gerakan tersebut dikenal dengan green school. Gerakan hijau di sekolah bukan berarti sekolah tersebut semuanya serba hijau dan rindang secara fisik, melainkan sekolah memiliki program dan aktivitas pendidikan yang mengarah pada penyadaran, kearifan, dan kepedulian akan lingkungnan hidup. ${ }^{2}$ Go green bisa diselenggarakan manakala semua warga di lingkungan sekolah memahami tentang hortikultur dan ekologi. Makna go green dalam arti luas adalah sekolah yang memiliki komitmen dalam mengembangkan nilai-nilai lingkungan hijau di lembaga. ${ }^{3}$ Oleh karena itu, tampilan fisik sekolah harus mencerminkan tata kelola ekologis sehingga menjadi wahana pembelajaran bagi seluruh warga sekolah. Dan hal inilah yang menjadikan peserta didik sebagai generasi penerus akan

\footnotetext{
1 Pratima Bansal dan Kendall Roth, "Why Companies Go Green: A Model of Ecological Responsiveness," Academy of Management Journal 43, no. 4 (1 Agustus 2000): 717-36, https://doi.org/10.5465/1556363.

2 Kementerian Negara Lingkungan Hidup, Panduan Adiwiyata: Wujudkan Sekolab Peduli dan Berbudaya Lingkungan (Jakarta: Kementerian Negara Lingkungan Hidup, 2009), 9.

${ }^{3}$ Chelsea Schelly dkk., "How to Go Green: Creating a Conservation Culture in a Public High School Through Education, Modeling, and Communication," The Journal of Environmental Education 43, no. 3 (2012): 143-161.
}

Volume 3, Number 2, November 2019| 143 Pengembangan Sekolah Berbasis Go Green dan Waste Manajemen untuk Mewujudkan Green School di SDI Miftahul Huda Plosokandang Kabupaten Tulungagung 
memiliki sikap arif dan berperilaku ramah lingkungan. ${ }^{4}$

Go green merupakan suatu gerakan, sedangkan aktualisasinya di sekolah adalah program green school atau dikenal dengan adiwiyata. Maksud program ini adalah membangun kesadaran sekolah sekaligus menggali partisipasi seluruh warga sekolah untuk mengintegrasikan semua kegiatankegiatan sekolah bermuatan pelestarian lingkungan. ${ }^{5}$ Tujuan dari program ini adalah membangun budaya sekolah dengan lingkungan sehat dan terhindar dari dampak lingkungan tercemar dan negatif. ${ }^{6}$ Salah satu hal yang menjadi penting dalam mewujudkan green school adalah sekolah menanggalakkan konsep hortikultur. ${ }^{7}$

Melihat kondisi lingkungan sekitar saat ini, konsep pengembangan sekolah berbasis hortikultur sangat penting untuk diimplementasikan lebih luas. Isu tentang pemanasan global yang disebabkan oleh peningkatan karbondioksida dan gas metana berimplikasi terhadap perubahan iklim. Hal ini bisa dilihat dari perubahan fluktuasi curah hujan yang cukup tinggi dan kenaikan permukaan air laut. ${ }^{8}$ Wiyono menyatakan bahwa perubahan iklim akan berdampak pada ledakan hama dan penyakit pada tanaman, ${ }^{9}$ serta kerusakan alam lain seperti bencana alam.

Halsey dan White (1998) dalam penelitiannya yang berjudul Crime, Ecophilosophy and Environmental Harm mengatakan berbagai bencana alam yang terjadi seperti banjir, tanah longsor, dan sebagainya, sebagian besar diakibatkan oleh perbuatan manusia yang merusak ekosistem lingkungan. ${ }^{10}$ Oleh karena itu perlu dilakukan upaya penyadaran agar manusia makin ramah pada lingkungan dan itu harus dibekalkan sejak usia dini agar tertanam dalam diri generasi penerus sekaligus menjadi karakter karena merupakan budaya sebagai akibat pembiasaan.

Di sinilah, konsep pengembangan sekolah berbasis go green dalam menumbuhkan sikap peduli lingkungan melalui proses pembelajaran dan pembiasaan menjadi penting dan strategis. Di sekolah, proses pembelajaran mengarah pada upaya pembentukan perilaku siswa yang peduli lingkungan melalui model pembelajaran yang aplikatif dan menyentuh kehidupan sehari-hari.

${ }^{4}$ Ulfatur Rahmah, "Pengaruh Penerapan Green School sebagai Strategi Pemasaran Pendidikan Terhadap Minat Siswa Kelas VII di Sekolah Menengah Pertama Negeri Surabaya” (PhD Thesis, UIN Sunan Ampel Surabaya, 2014).

5 Amanda Leigh Mascarelli, How Green Is Your Campus? (Nature Publishing Group, 2009).

${ }^{6}$ Kementerian Negara Lingkungan Hidup, Panduan Adiwiyata: Wujudkan Sekolah Peduli dan Berbudaya Lingkungan, 9.

7 Kathryn Karsh, "Integrating horticulture biology and coastal environmental issues into the Middle School Science Curriculum,” LSU Master's Theses, 1 Januari 2005, https://digitalcommons.lsu.edu/gradschool_theses/3602.

8 Amang Fathurrohman dkk., "Implementasi Manajemen Bank Sampah IT pada Komunitas Bank Sampah berbasis Masyarakat, Pemuda, dan Sekolah di Kabupaten Pasuruan," Engagement: Jurnal Pengabdian Kepada Masyarakat 2, no. 2 (2018): 154.

${ }^{9}$ Suryo Wiyono, "Perubahan Iklim Dan Ledakan Hama dan Penyakit Tanaman," dalam Di dalam: Seminar Sehari tentang Keanekaragaman Hayati Di tengah Perubahan Iklim: Tantangan Masa Depan Indonesia, 2007.

10 Mark Halsey dan Rob White, "Crime, Ecophilosophy and Environmental Harm," Theoretical Criminology 2, no. 3 (1 Agustus 1998): 345-71, https://doi.org/10.1177/1362480698002003003. 
Lingkungan sekolah dijadikan wahana pembiasaan perilaku peduli lingkungan sehari-hari. Dengan demikian, kedua aspek tadi, menuju pada satu tujuan yaitu internalisasi atau pembiasaan perilaku peduli lingkungan dalam kehidupan sehari-hari.

Fenomena tersebut terjadi di Sekolah Dasar Islam (SDI) Miftahul Huda, sebuah sekolah rintisan yang berbasis hortikultura. SDI Miftahul Huda terletak di Desa Plosokandang Kecamatan Kedungwaru, Tulungagung secara geografis berada di pinggiran kota dan termasuk area yang terkena dampak pembangunan pemukiman penduduk, pembangunan perumahan oleh developer, pembangunan rumah kos oleh para penduduk luar kota yang memiliki saham dikarenakan lokasi dekat dengan kampus yang sedang berkembang pesat. Hal ini mengakibatkan luas tanah semakin menyempit, pohon-pohon besar mulai ditebang, iklim menjadi panas dan polusi udara meningkat.

Perlu disadari bahwa semakin menyempitnya lahan dan produktivitas pertanian akibat pembangunan pemukiman, bisa berimbas pada berbagai hal seperti: (1) menurunnya kualitas kesehatan sebagai dampak perubahan iklim bagi generasi penerus kita; (2) minimnya pengetahuan generasi penerus tentang adapatsi terhadap perubahan iklim; dan (3) minimnya akses dalam menentukan kebijakan pengelolaan sumber daya alam.

Oleh karena itu pemberdayaan terhadap generasi penerus sejak usia dini ${ }^{11}$ melalui sekolah Islam berbasis hortikultur dalam mewujudkan gerakan go green yang dilaksanakan dengan mempertimbangkan potensi internal sekolah seperti: ketersediaan lahan, sumber daya air, energi, bentang alam, tradisi masyarakat sekitar, dan ekosistemnya yang merupakan objek pengembangan dalam konsep pengembangan sekolah berbasis hortikultur dan pengelolaan sampah (waste management). Inilah tantangan dalam community engagement untuk memberikan bekal pemberdayaan dan penyadaran kepada generasi penerus terhadap kepedulian lingkungannya pada masyarakat pinggiran kota.

Kajian Chen \& Cheng menunjukkan pendidikan peduli Lingkungan merupakan alat yang sangat penting dalam menyediakan pengetahuan, sikap positif terhadap lingkungan serta membangun keterampilan untuk melindungi dan meningkatkan kualitas lingkungan. Pendidikan lingkungan sejak dini menjadi urgen untuk membantu anak memiliki kesadaran yang tinggi terkait dengan pelestarian lingkungan hidup, meskipun peraturan mengenai pelaksanaan pendidikan lingkungan hidup telah lahir. ${ }^{12}$ Lebih lanjut Bencsik, Csikos, dan Juhez juga memantabkan bahwa

${ }^{11}$ Generasi penerus era sekarang masuk pada generasi Z, menurut Bencsik, Csikos, dan Juhez generasi Z adalah generasi multitasking yang menguasai informasi dan teknologi. Untuk itu edukasi pengenalan lingkungan untuk menjaga alam dan bumi berpijak menjadi penting diberikan agar mampu mengintegrasikan alam nyata ini dengan kemajuan teknologi dan informasi. Lihat dalam Yanuar Surya Putra, "Theoritical Review: Teori Perbedaan Generasi," Jurnal Ilmiah Among Makarti 9, no. 18 (2017).

12 Judith Chen-Hsuan Cheng, Children, Teachers and Nature: An Analysis of an Environmental Education Program 
generasi sekarang adalah generasi Z, suatu generasi multitasking yang menguasai informasi dan teknologi. Dalam hal ini edukasi pengenalan lingkungan untuk menjaga alam dan bumi berpijak menjadi penting diberikan agar mampu mengintegrasikan alam nyata ini dengan kemajuan teknologi dan informasi. ${ }^{13}$ Bezzina pun menyatakan kerusakan alam merupakan masalah krusial bukan masalah sosial semata. ${ }^{14}$

Pentingnya membangun kepedulian lingkungan ini juga dikaji oleh Nurmayanti dalam strategi pengembangan ecological citizenship Yayasan Mangrove Center Tuban, dimana didapatkan strategi membangun kesadaran bersama melalui program pembinaan sekolah peduli lingkungan yang mampu mewujudkan konservasi lingkungan dan pemberdayaan ecogreen. ${ }^{15} \mathrm{Hal}$ ini diperkuat oleh kajian Gusmadi dalam penelitiannya yang menunjukkan penguatan karakter peduli lingkungan harus dibangun melalui pendidikan karena generasi penerus yang berkontribusi dalam komunitas untuk bergerak, mengelola, peduli, dan melestarikan lingkungan. ${ }^{16}$ Gerakan go green ini menjadi menarik untuk dikaji, mengingat kunci dari membangun kesadaran untuk peduli pada lingkungan semakin kuat manakala dibangun sejak dini, melalui sekolah. Hal ini senada dengan pemberdayaan yang dilakukan Fathurrahman, dimana membangun kesadaran pengelolaan sampah juga dimulai dari komunitas dan sekolah. ${ }^{17}$

\section{Metode}

Metode yang diterapkan dalam pendampingan ini adalah metode Community Based Research. ${ }^{18}$ Mengacu pada pendapat Sarah Banks dari Center for Social Justice and Communit Action, Durham University ${ }^{19}$ Community Based Research (CBR) adalah salah satu metode kajian

(University of Florida, 2008); Moch Khafidz Fuad Raya, “Terapi Komunikasi Terapeutik Islam untuk Menanggulangi Gangguan Psikologis Anak Korban Bullying," dalam Proceedings of Annual Conference for Muslim Scholars, 2018, 321-329.

${ }^{13}$ Putra, "Theoritical Review."

${ }^{14}$ C. Bezzina dan Paul Pace, "School Improvement, School Effectiveness or Scholl Development," Creating Sustainable Environments in Our Schools. Stoke on Trent: Trentham Books, 2006, 11-28.

15 Ida Nurmayanti Nurmayanti dan Hermanto, "Strategi Yayasan Mangrove Center Tuban Dalam Mengembangkan Ecological Citizenship Pada Masyarakat Tuban," Jurnal Kajian Moral Dan Kewarganegaraan 5, no. 2 (t.t.): 83-97.

16 Setiawan Gusmadi, "Keterlibatan Warga Negara (Civic Engagement) dalam Penguatan Karakter Peduli Lingkungan," JUPIIS: JURNAL PENDIDIKAN ILMU-ILMU SOSLAL 10, no. 1 (2018): 31-37.

${ }^{17}$ Fathurrohman dkk., "Implementasi Manajemen Bank Sampah IT pada Komunitas Bank Sampah berbasis Masyarakat, Pemuda, dan Sekolah di Kabupaten Pasuruan."

18 Tim Penyusun CBR UIN Sunan Ampel Surabaya, Community Based Research: Sebuah Pengantar (Surabaya: SILE/LLD, 2015); Amang Fathurrohman, "Rintisan Pendidikan Anak Usia Dini Suku Tengger di Wilayah Terpencil Dusun Surorowo Desa Kayukebek Kecamatan Tutur Kabupaten Pasuruan," dalam Proceedings of Annual Conference for Muslim Scholars, 2017, 408-416.

${ }^{19}$ Sarah Banks dan Paul Manners, "Community-Based Participatory Research: A Guide to Ethical Principles and Practice," Durbam, UK: Center for Social Justice and Community Action, Durham University, 2012, 6.

Volume 3, Number 2, November 2019| 146 


\section{ENGAGEMENT}

Lurnal Pengabdian Kepada Masyarakat

ISSN : 2579-8375 (Print)

ISSN : 2579-8391 (Online)
This work is licensed under a Creative Commons Attribution-ShareAlike 4.0 International License. CC BY SA

berbasis komunitas (komunitas dalam pendampingan ini adalah SDI Miftahul Huda) yang memberikan dukungan, daya dan juga keterlibatan aktif dalam proses pemberdayaan dalam rangka menghasilkan sesuatu yang bermanfaat bagi mereka dan juga pengabdi yang terlibat. Metode community based research memperhatikan identifikasi problema serta upaya preventif bagi masyarakat, identifikasi proritas dukungan dan pengembangan sistem serta pembangunan social, identifikasi pengembangan program yang fokus pada masyarakat, dan menjawab kebutuhan masyarakat. Adapun tahap-tahap metode CBR adalah sebagai berikut: peletakan dasar (laying the foundation), perencanaan penelitian (research planning), pengumpulan dan analisis data (information gathering and analysis), dan aksi atas temuan (acting on findings). ${ }^{20}$

Penerapan metode ini diawali dengan kepedulian kepala sekolah (Agus Widodo) terhadap isu global warming. Melalui pendampingan, kepala sekolah melakukan pertemuan lanjutan dengan pihak guru dan terkait guna merumuskan visi dan misi lembaga yang berciri peduli lingkungan dengan menggali potensi yang mereka miliki berdasar pendekatan Asset Based Approach (ABA), ${ }^{21}$ yang meliputi penggalian aset sumber daya manusia, alam, fisik, dan social. Dari pertemuan ini terumus kesepakatan bersama menjadikan sekolah sebagai green school (laying the foundation). Selanjutnya Kepala sekolah, jajaran guru bersama dengan komite mengadakan workshop sekolah berbasis go green sekaligus untuk menyusun perangkat pembelajaran lingkungan hidup yang terintegrasi dalam kurikulum. Melalui capacity building itu muncullah kesadaran bersama akan dampak global warming dan harus ada aksi tindakan bersama. Akhirnya terusmuslah beberapa program aksi yang diterapkan sekolah. Program aksi tersebut didukung oleh habitus yang diterapkan, pun juga penciptaan lingkungan area sekolah (planning and information gathering). Berangkat dari perumusan, workshop, penciptaan habitus buang sampah pada tempatnya dan cintai tanaman ini maka atas prakarsa kepala sekolah (Agus Widodo) sebagai leader program, seluruh warga sekolah terlibat dalam aksi sebagai acting on finding yaitu berupa: pengembangan kurikulum berwawasan lingkungan yang terintegrasi, peningkatan kualitas kawasan sekolah dan lingkungan sekitarnya, dan pengembangan manajemen sekolah berwawasan lingkungan dan sistem pendukung yang ramah lingkungan. Adapun skema pemberdayaan sebagaimana gambar di bawah ini:

20 Martin Mulligan dan Yaso Nadarajah, "Working on the Sustainability of Local Communities with a 'Community-Engaged' Research Methodology,” Local Environment 13, no. 2 (2008): 81-94.

${ }^{21}$ Abdur Rozaki dan Siti Rohaya, "Memberdayakan Desa Melalui Pariwisata Berbasis BUMDES," Engagement: Jurnal Pengabdian Kepada Masyarakat 3, no. 1 (2019): 1-20; Gary Paul Green dan Anna Haines, Asset Building \& Community Development (Sage publications, 2015). 


\section{ENGAGEMENT}

Lurnal Pengabdian Kepada Masyarakat

ISSN : 2579-8375 (Print)

ISSN : 2579-8391 (Online)
This work is licensed under a Creative Commons Attribution-ShareAlike 4.0 International License.

CC BY SA

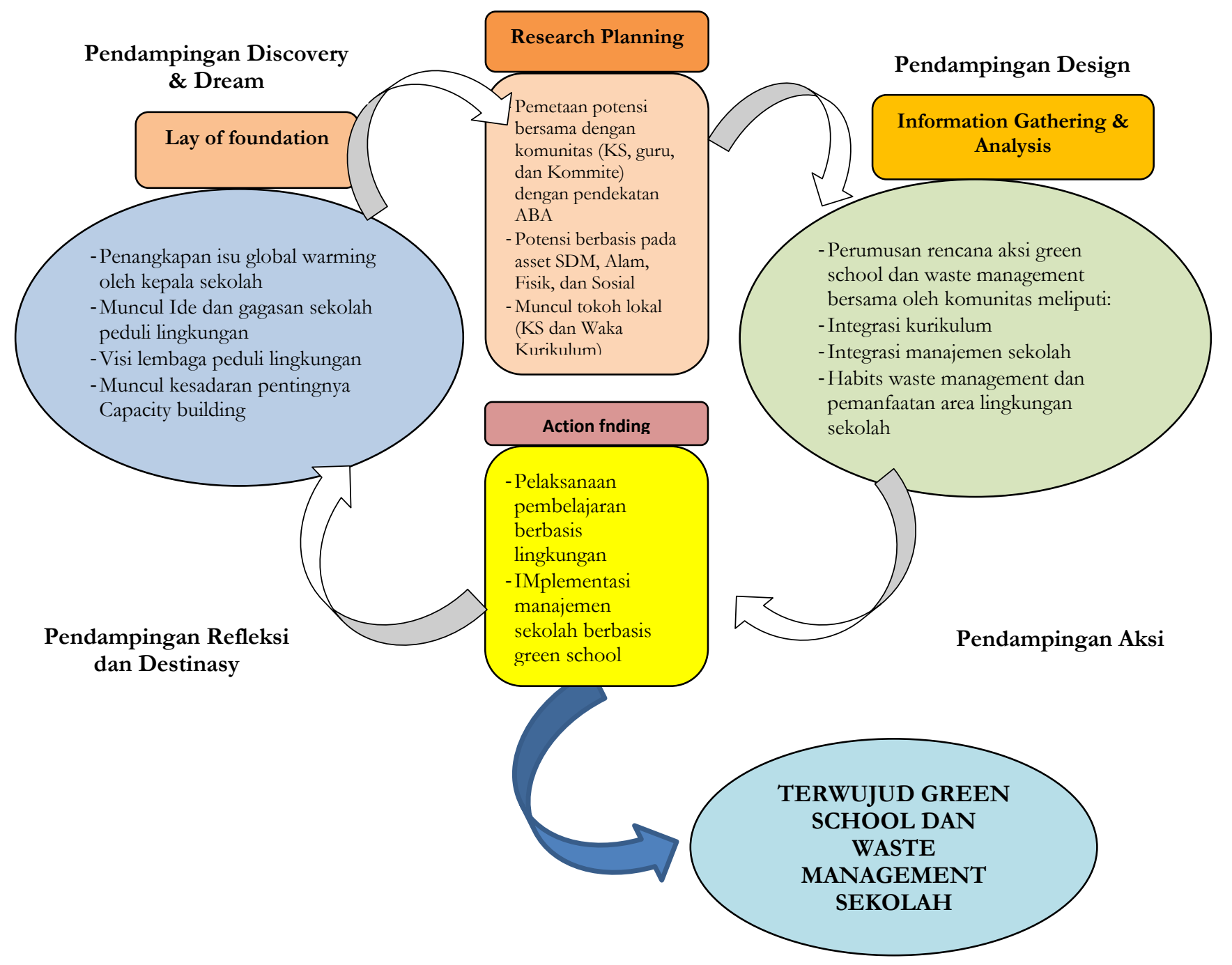

Gambar 1 Alur Pendampingan

\section{Hasil dan Diskusi}

\section{Proses Pemberdayaan}

Pemberdayaan yang dilakukan peneliti pada warga sekolah di SDI Miftahul Huda Plosokandang berawal dari kepedulian kepala sekolah terhadap global warming lalu meuncullah kesadaran akan pentingnya penanaman sikap peduli pada lingkungan sejak dini setelah melallui proses diskusi. Berangkat dari sini kepala sekolah menjadi tokoh local yang mampu menggerakkan para guru, siswa dan komite untuk mengaktualisasikan ide tersebut melalui pencanangan program green school. Siklus pemberdayaan diawali dengan pemetaan aset yang dimiliki oleh lembaga, yaitu aset sumberdaya manusia dan sumberdaya alam. SDI Mifathul Huda merupakan sekolah dasar yang terletak di pinggiran kota mendapat limpahan aset alam dengan lokasi yang berhimpitan 


\section{ENGAGEMENT}

Lurnal Pengabdian Kepada Masyarakat

ISSN : 2579-8375 (Print)

ISSN : 2579-8391 (Online)
This work is licensed under a Creative Commons Attribution-ShareAlike 4.0 International License. CC BY SA

dengan kampus IAIN Tulungagung yang mengalami perkembangan pesat. Sumber daya manusia ada dua puluh lima tenaga pendidikan dan kependidikan yang notabene lulusan pascasarjana dan tergolong usia produktif, sementara peserta didik mayoritas dari perkotaan termasuk para putraputri bapak/ibu dosen IAIN Tulungagung. Sistem full day dengan integrasi kurikulum berbasis religious yang kuat menjadikan paguyuban orang tua wali murid juga pro aktif dalam kegiatan sekolah. Di sisi lain aset sumber daya alam, letak geografis sekolah semakin terdesak oleh pemukiman penduduk, lahan semakin menyempit, terletak di pinggir rel kereta api sehingga tidak bisa melakukan perluasan area yang berdampak pada semakin meningkatnya pemanasan global. Pemetaan dilanjutkan dengan penggalian aset fisik dan sosial. Berdasar pemetaan tersebut, kepala sekolah (Agus Widodo) beserta guru lain bersepakat untuk melakukan gerakan go green sebagai aksi nyata kepedulian sekolah terhadap penyelamatan bumi demi generasi penerus. Hadirnya tokoh lokal dalam pemberdayaan ini menjadi urgen karena mampu menggerakkan orang lain untuk turut serta berpartisipasi. Pentingnya tokoh lokal ini sebagaimana pemberdayaan yang dilakukan Masrizal dalam menangani dampak gempa dan Tsunami Aceh menghasilkan peran tokoh lokal sebagai ujung tombak keberhasilan pemberdayaan. ${ }^{22}$

Inisiasi dari kepala sekolah yang turut didukung oleh para guru dan komite sekolah inilah titik awal perubahan, sebagaimana pendapat Nurcholis Madjid yang menyatakan bahwa harus ada pemimpin (Kepala Sekolah) yang memiliki kesadaran tinggi terhadap lembaga, mengingat lembaga pendidikan adalah sebagai agent of social change bagi masyarakat di tengah-tengah perubahan global ${ }^{23}$, sehingga Kepala Sekolah yang juga sebagai “manajer" di dalam institusinya harus dapat membawa perubahan yang lebih baik. ${ }^{24}$ Perubahan yang dilakukan lembaga melalui empat tahapan, yaitu yang terumus dalam $4 \mathrm{D}$, yaitu: discovery, dream, design, destiny.

Pertama, discovery (penelusuran), kepala sekolah, guru, dan komite (warga sekolah) melakukan penggalian aset yang ada (sumberdaya daya manusia, sumberdaya alam, fisik, dan social), dengan melakukan identifikasi sampai ke akarnya. Proses pengidentifikasian aset ini diawali dengan potensi sumber daya manusia. Hasil penggalian data menunjukkan SDI Miftahul Huda memiliki potensi SDM sebanyak 25 guru yang mayoritas sudah S2, peserta didik dari kalangan

22 M. Si Soetomo, "Peran Tokoh Informal Dalam Pemberdayaan Masyarakat: Studi Terhadap Penanganan Dampak Gempa Dan Tsunami Di Gampong Rukoh Kecamatan Syiah Kuala Kota Banda Aceh Provinsi Aceh" (PhD Thesis, [Yogyakarta]: Universitas Gadjah Mada, 2009).

${ }^{23}$ Nurcholish Madjid dan Islam Doktrin, "Peradaban," Jakarta: Paramadina, 1995; Ridwan Idris, "Pendidikan Sebagai Agen Perubahan Menuju Masyarakat Indonesia Seutuhnya," Lentera Pendidikan: Jurnal Ilmu Tarbiyah dan Keguruan 16, no. 1 (2013): 62-72.

${ }^{24}$ Moch Khafidz Fuad Raya, "Komunikasi Manajerial Dalam Pendidikan," Wasilatuna: Jurnal Komunikasi dan Penyiaran Islam 1, no. 1 (2018): 60-74. 


\section{ENGAGEMENT}

Lurnal Pengabdian Kepada Masyarakat

ISSN : 2579-8375 (Print)

ISSN : 2579-8391 (Online)
This work is licensed under a Creative Commons Attribution-ShareAlike 4.0 International License.

ekonomi menengah ke atas, latar belakang heterogen, dan input dari masyarakat perkotaan. Potensi alam di pinggiran kota, polusi sudah mulai merambah, lahan sempit, pinggir kota, perluasan area tidak memungkinkan, kesadaran membuang sampah pada di sungai belum maksimal. Aset sosial, dukungan dari tokoh masyarakat dan tokoh agama kuat, supporting wali murid yang baik. Aspek historis sejarah, kabupaten Tulungagung berada di lokasi bagian selatan pulau Jawa, terutama Jawa Timur, dimana secara historis pantai selatan digunakan sebagai kawah condrodimuko untuk padepokan Ratu Gayatri, termasuk bukit penampihan yang peninggalannya masih ada hingga saat ini. Hal ini menandakan letak geografis daerah Tulungagung merupakan wilayah yang asri sebagai paru-paru dunia. Namun kondisi sekarang sudah mulai terjamah dan hutan sudah mulai gundul.

Penelusuran ini menimbulkan suatu impian, Kota Tulungagung bisa berubah lagi menjadi asri seperti dahulu kala manakala generasi penerusnya sadar akan lingkungan dan menjaga bumi ini bersih dari pencemaran. Inilah yang menjadi tahap kedua dalam perubahan, yaitu dream. Selanjutnya warga sekolah mengerucutkan impian tersebut dalam suatu kesepakatan bahwa sekolah harus memberikan bekal edukasi sejak awal kepada generasi penerus tentang gerakan peduli lingkungan dan kesadaran membuang sampah pada tempatnya dan terumuslah inisiasi dan keputusan sekolah SDI Miftahul Huda mencanangkan sebagai sekolah go green. Inilah tahap ketiga perubahan, yaitu design. Dalam tahap design ini dilakukan pengelolaan mulai planning, organizing, actuating, hingga evaluating, yang mana implementasinya melalui kegiatan-kegiatan pemberdayaan yang dipaparkan berikut dibawah ini, yang mana kesemuanya untuk mencapai tahap keempat, yaitu destiny. Model pemberdayaan 4D (discovery, dream, design, dan destiny) ini sebagaimana pemberdayaan yang dilakukan oleh Rozaki dalam mendampingi desa melalui pariwisata berbasis Bumdes di Gunungkidul Jogyakarta. ${ }^{25}$

Aksi kegiatan pemberdayaan yang dilakukan berdasar penggalian potensi empat aset komunitas adalah sebagai berikut:

\section{Kegiatan Pengembangan Kurikulum Berwawasan Lingkungan dan Pendidikan Berbasis}

\section{Komunitas.}

\section{Diklat Lingkungan Hidup bagi Guru}

Kegiatan diklat ini muncul sebagai tindak lanjut dari kesepakatan bersama tentang pencanangan sekolah go green dan waste management. Sebelum melangkah lebih lanjut, SDM guru perlu disiapkan untuk penyamaan persepsi dan penyusunan kurikulum yang peduli lingkunngan secara terintegrasi. Akhirnya diklat ini sebagai aksi kegiatan yang dilakukan dalam community

${ }^{25}$ Rozaki dan Rohaya, "Memberdayakan Desa Melalui Pariwisata Berbasis BUMDES.” 


\section{ENGAGEMENT}

Lurnal Pengabdian Kepada Masyarakat

ISSN : 2579-8375 (Print)

ISSN : 2579-8391 (Online)
This work is licensed under a Creative Commons Attribution-ShareAlike 4.0 International License.

CC BY SA

engagement pengembangan kurikulum berwawasan lingkungan melalui capacity building terhadap sumber daya manusianya dulu, yaitu para bapak dan ibu guru melalui kegiatan pelatihan dan pendidikan tentang lingkungan hidup. Kegiatan diklat dilaksanakan di kedua sekolah tersebut, yaitu bagi guru di lingkungan SDI Miftahul Huda Tulungagung. Diklat diikuti oleh 25 guru. Peserta sangat antusias, karena mereka menyadari pentingnya penanaman sejak dini jiwa cinta lingkungan kepada peserta didik.

Secara khusus diklat ini sebagai bekal pada bapak/ibu guru dalam menerapkan kurikulum yang terintegrasi dengan lingkungan hidup, dan secara umum, diklat ini juga sebagai pembelajaran lingkungan hidup bagi seluruh warga sekolah/madrasah yang akhir-akhir ini telah dan semakin marak diterapkan. Paradigma lama harus sudah diubah, bahwa dalam penerapan suatu kurikulum, orientasi bukan memperlakukan siswa sebagai pekerja di lingkungan sekolah, tetapi membangun jiwa cinta lingkungan, dengan harapan bahwa generasi berikut menjadi generasi yang berbudaya lingkungan dan menjadi sebuah habit bagi semua civitas sekolah.

Narasumber yang didatangkan adalah doktor konsentrasi Biologi, yang disertasinya membuahkan modul pembelajaran tentang pengelolaan sampah. Sehingga dalam diklat ini sekaligus para bapak dan ibu guru dibekali dengan buku modul berikut materi audio visual dalam bentuk VCD dan juga buku saku tentang pengelolaan sampah yang diberikan kepada siswa-siswi SDI Miftahul Huda.

Selanjutnya untuk mencapai maksud tersebut di atas, program community engagement melangkah pada program berikutnya yaitu sosialisasi program kepada siswa-siswi selaku peserta didik.

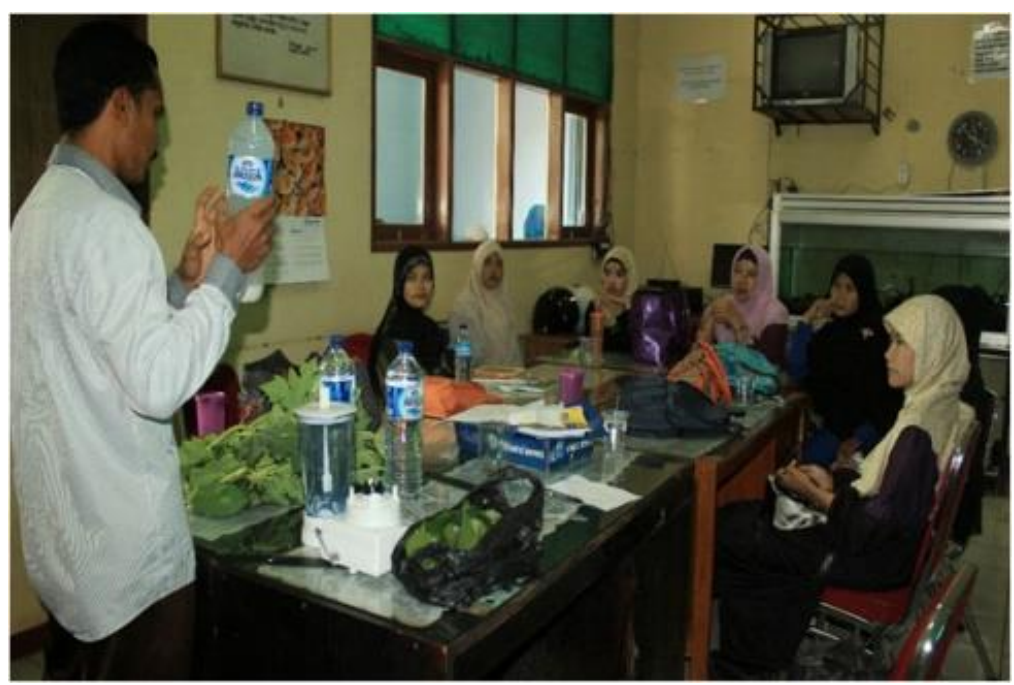

Gambar 2 Diklat Lingkungan Hidup bagi Guru

Volume 3, Number 2, November 2019| 151

Pengembangan Sekolah Berbasis Go Green dan Waste Manajemen untuk Mewujudkan Green School di SDI Miftahul Huda Plosokandang Kabupaten Tulungagung

Chusnul Chotimah 


\section{ENGAGEMENT}

Lurnal Pengabdian Kepada Masyarakat

ISSN : 2579-8375 (Print)

ISSN : 2579-8391 (Online)
This work is licensed under a Creative Commons Attribution-ShareAlike 4.0 International License.

CC BY SA

\section{Sosialisasi Sekolah berbasis Green School dan Waste Management (Pengolahan}

Sampah)

Aksi community engagement selanjutnya adalah sosialisasi kepada siswa-siswa SDI Miftahul Huda tentang pentingnya kita menjaga lingkungan hidup dan bagaimana sikap kita terhadap sampah. Hal ini bertujuan untuk mencapai konsistensi holistik antara guru dengan siswa-siswi tentang peran lingkungan terhadap keberlangsungan kehidupan di bumi, ancaman terhadap kehidupan dan solusi penyelamatan kehidupan di bumi, serta menjelaskan tentang porsi perhatian sekolah dalam hal ini siswa terhadap ekosistem lingkungan hidup sekitarnya.

Selain sosialisasi tentang lingkungan hidup yang mengarah pada sekolah hijau, juga tentang pengolahan sampah, yang mana program sosialisasi ini membelajarkan kepada siswa-siswi tentang bagaimana seharusnya perilaku kita terhadap sampah, pemahaman tentang sampah organik dan anorganik berikut pemilahan sampahnya hingga akhir pada proses pembuatan pupuk kompos. Metode pembelajaran dengan menggunakan media audio visual sehingga siswa-siswi lebih bisa mengetahui sesuai dengan konteks realita yang ada.

\section{Peningkatan kualitas kawasan sekolah dan lingkungan sekitarnya.}

Aksi community engagement dalam peningkatan kualitas kawasan sekolah dan lingkungan sekitarnya bisa dilaksanakan dalam bidang ekstrakurikuler. Kegiatan ini dilaksanakan setelah dilakukan diklat dan sosialisasi tentang lingkungan hidup sekolah/madrasah berbasis hortikultur dengan pendekatan melakukan aksi langsung di lapangan yang dikemas dalam program visit site project ke Kampung Tani.

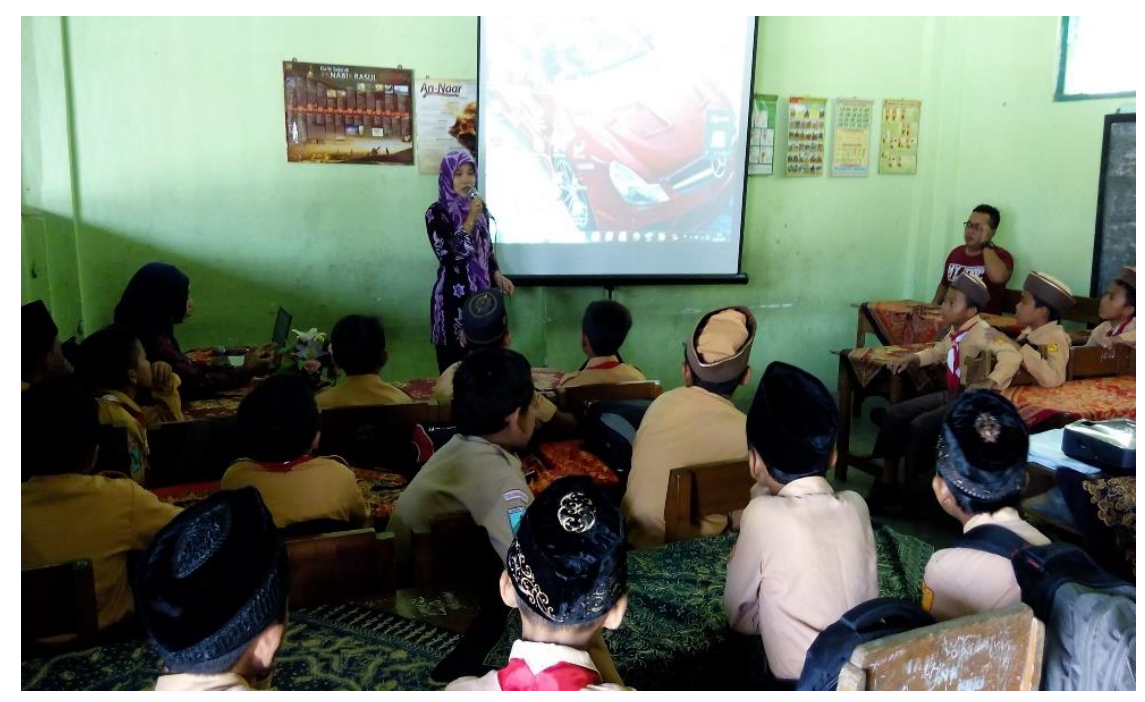

Gambar 3 Sosialisasi di SDI Miftahul Huda

Volume 3, Number 2, November 2019| 152 Pengembangan Sekolah Berbasis Go Green dan Waste Manajemen untuk Mewujudkan Green School di SDI Miftahul Huda Plosokandang Kabupaten Tulungagung 


\section{ENGAGEMENT}

Lurnal Pengabdian Kepada Masyarakat

ISSN : 2579-8375 (Print)

ISSN : 2579-8391 (Online)
This work is licensed under a Creative Commons Attribution-ShareAlike 4.0 International License. CC BY SA

Di Kampung Tani siswa-siswi SDI Miftahul Huda mendapatkan pengalaman langsung tentang menjaga lingkungan hidup, mulai tata cara menanam dan merawat tumbuhan organik non pestisida di lokasi, praktek langsung tata cara pengolahan sampah dan pembuatan kompos. Pengalaman lanngsung ini merupakan implementasi dari pembelajaran kontekstual melalui visit site project ke kampung tani yang dikemas dalam kegiatan outbond, sehingga selain siswa mendapatkan pengalaman edukatif, juga memperoleh pembelajaran yang menyenangkan.

Selain itu visit site project juga bertujuan untuk melibatkan siswa-siswi secara langsung bagaimana melakukan belajar dan pembelajaran yang bersentuhan langsung dengan alam (pembelajaran kontekstual). Siswa-siswi mendapatkan pembelajaran sekolah alam dan back to nature, sehingga diharapkan dengan program ini akan memberikan pengalaman yang melekat pada diri siswa, menginspirasi, menerapkan dan yang akhirnya membentuk karakter siswa peduli terhadap lingkungan.

Bagi siswa SDI Miftahul Huda yang notabene adalah anak-anak dari perkotaan sangat antusias sekali mengikuti program ini, walau awalnya mereka merasa jijik untuk memegang tanah, bermain lumpur dan aktivitas di sungai. Namun, ketika program berjalan justru menunjukkan perilaku yang paradok dengan awal mula mereka datang mengikuti instruksi. Bersahabat dengan alam akan membagun karakter siswa-siswi belajar berbasis pada pengalaman dengan kegiatan alam terbuka sebagai media utama. Visit site programme yang dikemas dalam outbond ini membangun karakter tangguh, sifat-sifat kepemimpinan dan kemampuan bekerjasama yang didasari akhlak mulia

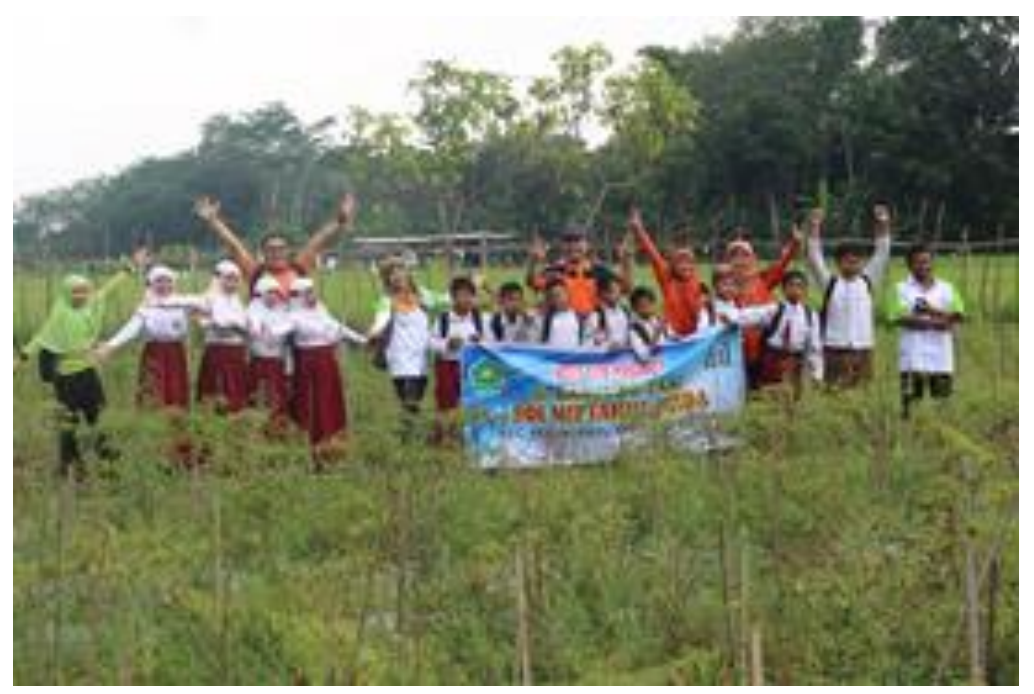

Gambar 4 Visite Site Programme 


\section{ENGAGEMENT}

Lurnal Pengabdian Kepada Masyarakat

ISSN : 2579-8375 (Print)

ISSN : 2579-8391 (Online)
This work is licensed under a Creative Commons Attribution-ShareAlike 4.0 International License. CC BY SA

Program visit site yang dikemas dalam outbond ini ternyata mampu: (a) menumbuhkan sikap kepemimpinan dan keberanian siswa-siswi dalam mengambil keputusan (dalam kelompok); (b) meningkatkan sportifitas yang dapat diterapkan dalam kegiatan kerja sehari- hari; (c) meningkatkan motifasi dalam kerjasama kelompok; (d) meningkatkan kemampuan berkomunikasi secara efektif; (e) menumbuhkan komitmen pada norma yang disepakati; (f) menumbuhkan semangat berkompetisi dalam konteks untuk mencapai tujuan bersama; (g) membangun sikap pantang menyerah dalam menyelesaikan permasalahan kerja; (h) melatih membuat perencanaan yang matang dan koordinasi tim yang rapi; dan (i) melatih kemampuan mengambil keputusan yang efektif dalam situasi sulit.

Sementara itu visit site programe juga selaras dengan program aksi yang pertama yaitu mengintengrasikan pendidikan lingkungan hidup dalam kurikulum sekolah, sehingga sekolah berbasis go green akan terwujud.

\section{Metode Belajar}

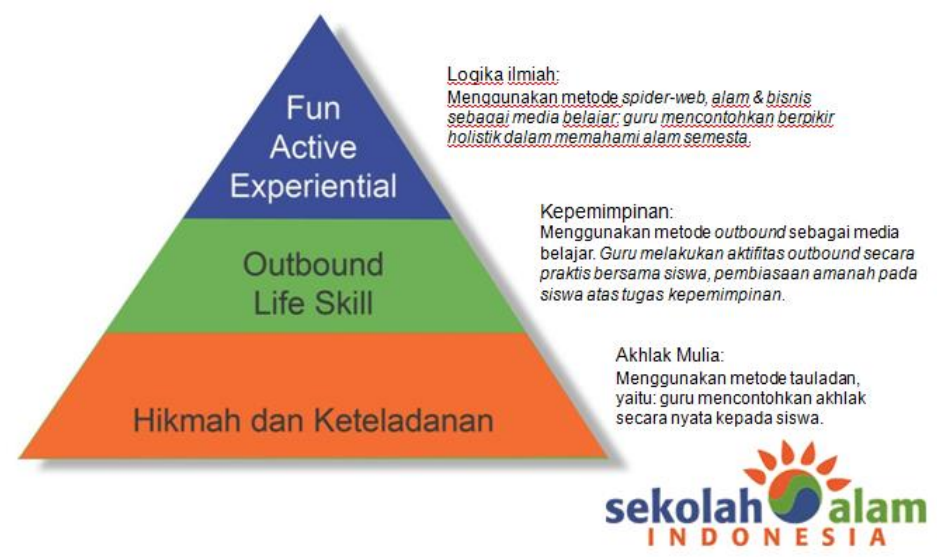

\section{Gambar 5 Desain Pembelajaran Sekolah Alam}

Penjelasan gambar tersebut di atas adalah, dengan outbond di Kampung Tani memberikan pembelajaran langsung tentang metode belajar dengan menggunakan metode ilmiah yang di kemas dalam fun active experiential, memupuk jiwa kepemimpinan siswa melalui team work, melatih siswa berpikir logis, mencari penelusuran langsung dengan alam sebagai aktualiasi dari berpikir holistik. Sementara sisi lain dengan outbond yang dilakukan di kampong tani mampu melatih skill para siswa dari yang semula merasa tidak nyaman dengan tanah, lumpur, tanaman, kompos, dan lainlain menjadi bersahabat dengan alam. Ternyata jika anak tidak dilarang dengan kata-kata 'kotor' justru siswa mampu ekspore secara maksimal. Selain itu skill yang terbangun adalah menanam pohon, pembuatan pupuk organik, dan perawatan tanaman. Manakala semua itu dilakukan melalui 
pembiasaan praktis bersama-sama dimulai dari sekolah maka menjadi life skill siswa. Dan hikmah dari ini semua adalah penanaman nilai moral akhlak karimah siswa.

\section{Pengembangan manajemen sekolah berwawasan lingkungan dan sistem pendukung yang ramah lingkungan.}

Aksi program community engagement selanjutnya adalah pengembangan manajemen sekolah/madrasah berbasis go green. Pendampingan kali ini memposisikan diri sebagai konsultan, supporting ide dan gagasan. Peneliti telah memberikan bekal kepada sekolah tentang program jangka panjang yang harus terintegrasi dalam visi misi sekolah, yaitu manajemen sekolah berwawasan lingkungan bersifat menyeluruh dan didukung oleh sistem yang ramah lingkungan. Program jangka panjang yang dilaksanakan sekolah meliputi: (1) Desain sekolah dengan standar penampilan fisik terbaik. Untuk SDI Miftahul Huda, kondisi saat ini sangat tepat untuk berbenah mendesain bangunan fisik, karena baru saja melakukan pembelian tanah seluas $\pm 750 \mathrm{~m}^{2}$. Pembelian tanah dialokasikan untuk penambahan pembangunan gedung sehingga program ke depan desain bangunannya memperhatikan aspek kepedulian lingkungan; (2) Penjagaan temperatur ruangan yang nyaman yang berasal dari sistem ventilasi yang baik; (3) Penggunaan material yang ramah lingkungan menghindari racun yang mempengaruhi kesehatan; (4) Efisiensi air di toilet dengan mengembangkan konsep pemanfaatan air hujan; (5) Melakukan daur ulang sampah; dan (6) Peningkatan fasilitas bersama dengan masyarakat.

Dari semua program tersebut di atas, yang menjadi sangat urgen dan bersifat kontinyu adalah manajemen lingkungan sosial dalam bentuk pembiasaan perilaku-perilaku nyata yang positif seperti: kedisiplinan, kerja sama, kepedulian, kejujuran, dan menghargai kearifan lokal yang tertanam pada diri seluruh warga sekolah. Hal inilah yang menjadi target community engagement.

Sedangkan program jangka pendek, baik telah maupun sedang berlangsung secara kontinyu adalah melakukan penataan ruang kelas dengan tingkat akustik yang tinggi, menciptakan lingkungan belajar yang lebih produktif untuk anak-anak dan memungkinkan guru didengar tanpa melelahkan suara mereka. Proses belajar anak tidak setiap hari di dalam kelas, melainkan kadang bisa diajak di luar kelas atau membuat desain kelas berubah-ubah. Selain itu pihak manajemen sekolah juga melakukan penataan pencahayaan berbasis alam (ventilasi yang baik) dan penggunaan lampu hemat energi. Disisi lain, ada juga gerakan kampanye penggunaan sistem transportasi ramah lingkungan dengan membudayakan pemakaian gowes to school, bersepeda ke sekolah. Hal ini gencar dilaksanakan oleh pihak sekolah untuk menjaga udara bebas dari polusi. 


\section{ENGAGEMENT}

Lurnal Pengabdian Kepada Masyarakat

ISSN : 2579-8375 (Print)

ISSN : 2579-8391 (Online)
This work is licensed under a Creative Commons Attribution-ShareAlike 4.0 International License.

CC BY SA

Dari paparan tersebut di atas, program aksi di sekolah yang telah dilaksanakan sebagai berikut: tahap pertama (diklat dan sosialisasi), tahap kedua (visit site programme), dan tahap ketiga adalah manajemen sekolah. Pada tahap ketiga ini pendampingan aksi yang dilakukan sebagai berikut:

Gerakan pemanfaatan dan penataan lahan sekolah menjadi laboratorium alam seperti menjadi kebun dan tanaman obat-obatan, ajakan hemat energi dan air. Ada 100 bibit tanaman toga yang ditanam di sekolah dengan melibatkan seluruh para siswa-siswi sekalgus untuk pembuatan laboratorium toga di sekolah.

Melakukan pembiasaan perilaku positif kepada seluruh warga sekolah tentang sampah. Mulai dari pemilahan sampah dari sampah organik dan an organik hingga pada pengolahan sampah menjadi kompos. Penguatan pada warga sekolah dilakukan mulai pembiasaan perilaku warga sekolah sampai dengan pengolahan sampah dengan proses reduce, reuse, dan recycle. Konsep 3R tersebut bisa diintegrasikan dalam mata pelajaran ketrampilan siswa. Siswa membuat ketrampilan dengan menggunakan bahan bekas.

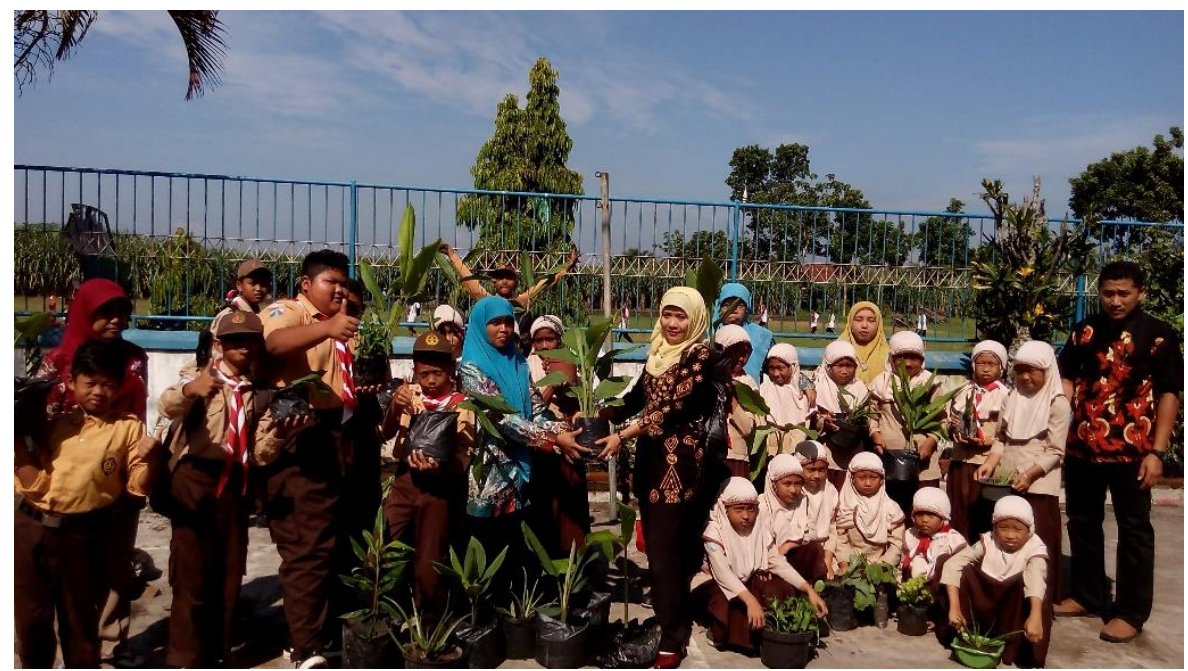

Gambar 6 Pengelolaan Bibit Tanaman

Adapun program aksi yang melibatkan manajemen sekolah bersama masyarakat sekitar adalah berpartisipasi langsung dalam penanaman hutan di gunung Pethuk kecamatan Junjung Tulungagung. Pihak sekolah bersama siswa-siswi, komite sekolah, wali murid dan masyarakat sekitar turut serta dalam program tersebut. Hal ini untuk memberikan pembelajaran secara langsung kepada semua pihak, termasuk pemangku kewenangan baik di sekolah maupun masyarakat luas. Program penanaman hutan ini melibatkan seluruh unsur elemen yang ada di kota Tulungagung, mulai dari dinas pendidikan, dinas sosial, pertanian, kehutanan, tokoh masyarakat, LSM dan pihak lain yang terkait. Ada bantuan 5760 bibit pohon akasia, sirsat, sengon, dan pohon 


\section{ENGAGEMENT}

Lurnal Pengabdian Kepada Masyarakat

ISSN : 2579-8375 (Print)

ISSN : 2579-8391 (Online)
This work is licensed under a Creative Commons Attribution-ShareAlike 4.0 International License. CC BY SA

mentega. Keterlibatan langsung dari SDI Miftahul Huda adalah gerakan solidaritas penyediaan 300

bibit pohon akasia, dan partisipasi langsung dalam penanaman pohon di hutan gunung Pethuk.

Dari serangkaian tahap aksi empowering yang telah dilakukan, pada dasarnya merupakan bentuk pemberdayaan dalam kerangka pembelajaran dan penyadaran bagi generasi penerus terhadap kepedulian lingkungan dan pengelolaan sampah yang berujung pada pembentukan kebiasaan perilaku-perilaku nyata yang positif di lingkungan sekitar.

Alur pemberdayaan program ini bisa digambarkan sebagaimana skema berikut di bawah ini:

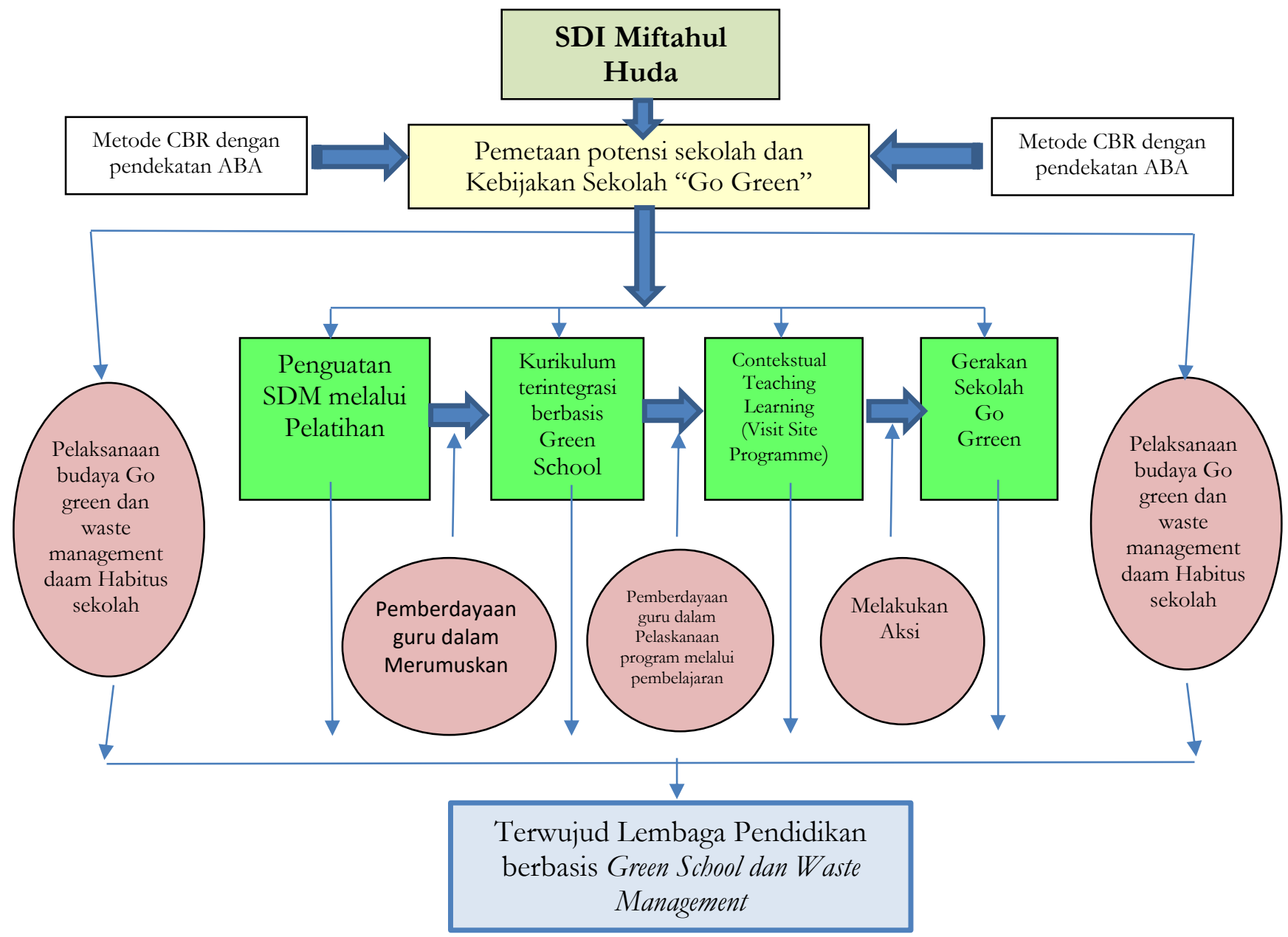

Gambar 7 Alur Program Pemberdayaan

Perubahan kondisi setelah dilakukan pemberdayaan adalah terwujudnya green school dan waste management di SDI Miftahul Huda yang terintegrasi dalam kurikulum dan pembelajaran seharihari dengan melibatkan partisipasi langsung dari pihak guru, komite, dan siswa. Terwujudnya green school ini meneguhkan kajian Wiyani, yang menyatakan bahwa sekolah yang menerapkan go green 
akan membantu mengurangi dampak pemanasan global yang akhir-akhir ini lapisan ozon bumi mulai berkurang. ${ }^{26}$ Capaian pemberdayaan di SDI Miftahul Huda diantaranya: kepedulian lingkungan terpatri dalam diri siswa, karakter kedisiplinan, kerja sama, kejujuran, dan menghargai kearifan lokal akan terbangun dengan sendirinya. Capaian ini menguatkan pernyataan Soeriatmadja yang mengatakan bahwa sekolah yang mencanangkan gerakan green school akan memberikan pembelajaran langsung pada peserta didik dan seluruh warga sekolah memiliki kesadaran dan kepekaan terhadap lingkungan hidup, dan sumberdaya alam secara totalitas. ${ }^{27}$ Namun perlu disadari bahwa pelaksanaan program ini bukan berarti semua yang ditargetkan akan tercapai, namun semua itu perlu proses dan berkesinambungan, di dukung oleh kebijakan yang berpihak terhadap lingkungan, munculnya tokoh local sebagai penggerak, dan partisipasi semua warga sekolah.

\section{Simpulan}

Demikian pemberdayaan komunitas yang telah dilakukan sebagai wujud dari program pengabdian dosen kepada masyarakat. Hasi dari pendampingan yang telah dilaksanakan mampu mewujudkan SDI Miftahul Huda menjadi sekolah berbasis pada green school dan waste management dengan memunculkan tokoh lokal sebagai penggerak, yaitu Kepala sekolah dan dukungan dari berbagai pihak, termasuk komite. Mata pelajaran Lingkungan Hidup terintegrasi dalam kurikulum, budaya hidup bersih, sikap peduli lingkungan, disiplin, dan tanggung jawab terbangun dan dibiasakan dalam kehidupan sehari-hari. Hasil pendampingan ini merekomendasikan sekolah lain untuk mencanangkan program serupa (Green School) mengingat pentingnya membangun kesadaran sikap peduli lingkungan kepada generasi penerus.

\section{Daftar Pustaka}

Banks, Sarah, dan Paul Manners. "Community-Based Participatory Research: A Guide to Ethical Principles and Practice." Durbam, UK: Center for Social Justice and Community Action, Durham University, 2012.

Bansal, Pratima, dan Kendall Roth. "Why Companies Go Green: A Model of Ecological Responsiveness." Academy of Management Journal 43, no. 4 (1 Agustus 2000): 717-36. https://doi.org/10.5465/1556363.

\footnotetext{
26 Novan Ardy Wiyani, "Manajemen kelas: Teori dan aplikasi untuk menciptakan kelas yang kondusif," Yogyakarta: Ar-Ruzz Media, 2013, 152-53.

27 Kementerian Negara Lingkungan Hidup, Panduan Adiwiyata: Wujudkan Sekolah Peduli dan Berbudaya Lingkungan, 6.
}

Volume 3, Number 2, November 2019| 158 


\section{ENGAGEMENT}

Lurnal Pengabdian Kepada Masyarakat

ISSN : 2579-8375 (Print)

ISSN : 2579-8391 (Online)
This work is licensed under a Creative Commons Attribution-ShareAlike 4.0 International License. CC BY SA

Bezzina, C., dan Paul Pace. "School Improvement, School Effectiveness or Scholl Development." Creating Sustainable Environments in Our Schools. Stoke on Trent: Trentham Books, 2006, 11-28.

Cheng, Judith Chen-Hsuan. Children, Teachers and Nature: An Analysis of an Environmental Education Program. University of Florida, 2008.

Fathurrohman, Amang. "Rintisan Pendidikan Anak Usia Dini Suku Tengger di Wilayah Terpencil Dusun Surorowo Desa Kayukebek Kecamatan Tutur Kabupaten Pasuruan.” Dalam Proceedings of Annual Conference for Muslim Scholars, 408-416, 2017.

Fathurrohman, Amang, M. Dayat, Zainul Ahwan, M. Daimul Abror, Lukman Hakim, Syukur Sugeng Apriwiyanto, Imam Syafi'i, Fafit Rahmat Aji, dan Mulyono Wobisono. "Implementasi Manajemen Bank Sampah IT pada Komunitas Bank Sampah berbasis Masyarakat, Pemuda, dan Sekolah di Kabupaten Pasuruan." Engagement: Jurnal Pengabdian Kepada Masyarakat 2, no. 2 (2018): 154-167.

Green, Gary Paul, dan Anna Haines. Asset Building \& Community Development. Sage publications, 2015.

Gusmadi, Setiawan. "Keterlibatan Warga Negara (Civic Engagement) dalam Penguatan Karakter Peduli Lingkungan.” JUPIIS: JURNAL PENDIDIKAN ILMU-ILMU SOSLAL 10, no. 1 (2018): 31-37.

Halsey, Mark, dan Rob White. "Crime, Ecophilosophy and Environmental Harm." Theoretical Criminology 2, no. 3 (1 Agustus 1998): 345-71. https://doi.org/10.1177/1362480698002003003.

Idris, Ridwan. "Pendidikan Sebagai Agen Perubahan Menuju Masyarakat Indonesia Seutuhnya." Lentera Pendidikan: Jurnal Ilmu Tarbiyah dan Keguruan 16, no. 1 (2013): 62-72.

Karsh, Kathryn. "Integrating horticulture biology and coastal environmental issues into the Middle School Science Curriculum." LSU Master's Theses, 1 Januari 2005. https://digitalcommons.lsu.edu/gradschool_theses/3602.

Kementerian Negara Lingkungan Hidup. Panduan Adiwiyata: Wujudkan Sekolab Peduli dan Berbudaya Lingkungan. Jakarta: Kementerian Negara Lingkungan Hidup, 2009.

Madjid, Nurcholish, dan Islam Doktrin. "Peradaban.” Jakarta: Paramadina, 1995.

Mascarelli, Amanda Leigh. How Green Is Your Campus? Nature Publishing Group, 2009.

Nurmayanti, Ida Nurmayanti, dan Hermanto. "Strategi Yayasan Mangrove Center Tuban Dalam Mengembangkan Ecological Citizenship Pada Masyarakat Tuban.” Jurnal Kajian Moral Dan Kewarganegaraan 5, no. 2 (t.t.): 83-97.

Putra, Yanuar Surya. “Theoritical Review: Teori Perbedaan Generasi.” Jurnal Ilmiah Among Makarti 9, no. 18 (2017).

Rahmah, Ulfatur. "Pengaruh Penerapan Green School sebagai Strategi Pemasaran Pendidikan Terhadap Minat Siswa Kelas VII di Sekolah Menengah Pertama Negeri Surabaya." PhD Thesis, UIN Sunan Ampel Surabaya, 2014.

Raya, Moch Khafidz Fuad. "Komunikasi Manajerial Dalam Pendidikan." Wasilatuna: Jurnal Komunikasi dan Penyiaran Islam 1, no. 1 (2018): 60-74.

- "Terapi Komunikasi Terapeutik Islam untuk Menanggulangi Gangguan Psikologis Anak Korban Bullying.” Dalam Proceedings of Annual Conference for Muslim Scholars, 321-329, 2018.

Rozaki, Abdur, dan Siti Rohaya. "Memberdayakan Desa Melalui Pariwisata Berbasis BUMDES." 


\section{ENGAGEMENT}

Lurnal Pengabdian Kepada Masyarakat

ISSN : 2579-8375 (Print)

ISSN : 2579-8391 (Online)
This work is licensed under a Creative Commons Attribution-ShareAlike 4.0 International License. CC BY SA

Engagement: Jurnal Pengabdian Kepada Masyarakat 3, no. 1 (2019): 1-20.

Schelly, Chelsea, Jennifer E. Cross, William Franzen, Pete Hall, dan Stu Reeve. "How to Go Green: Creating a Conservation Culture in a Public High School Through Education, Modeling, and Communication." The Journal of Environmental Education 43, no. 3 (2012): 143-161.

Soetomo, M. Si. "Peran Tokoh Informal Dalam Pemberdayaan Masyarakat: Studi Terhadap Penanganan Dampak Gempa Dan Tsunami Di Gampong Rukoh Kecamatan Syiah Kuala Kota Banda Aceh Provinsi Aceh.” PhD Thesis, [Yogyakarta]: Universitas Gadjah Mada, 2009.

Tim Penyusun CBR UIN Sunan Ampel Surabaya. Community Based Research: Sebuah Pengantar. Surabaya: SILE/LLD, 2015.

Wiyani, Novan Ardy. "Manajemen kelas: Teori dan aplikasi untuk menciptakan kelas yang kondusif." Yogyakarta: Ar-Ruгz.Media, 2013.

Wiyono, Suryo. "Perubahan Iklim Dan Ledakan Hama dan Penyakit Tanaman." Dalam Di dalam: Seminar Sehari tentang Keanekaragaman Hayati Di tengah Perubahan Iklim: Tantangan Masa Depan Indonesia, 2007. 